Article

\title{
Localized In Situ Nanoemulgel Drug Delivery System of Quercetin for Periodontitis: Development and Computational Simulations
}

\author{
Gururaj C. Aithal ${ }^{1}$, Usha Yogendra Nayak ${ }^{1, *}$ (D), Chetan Mehta ${ }^{1}$, Reema Narayan ${ }^{1}$, \\ Pratibha Gopalkrishna ${ }^{2}$, Sudharsan Pandiyan ${ }^{3}$ and Sanjay Garg ${ }^{4}$ \\ 1 Department of Pharmaceutics, Manipal College of Pharmaceutical Sciences, \\ Manipal Academy of Higher Education, Manipal 576104, India; gururajaithal262@gmail.com (G.C.A.); \\ chetan_jd12@rediffmail.com (C.M.); nsreema@gmail.com (R.N.) \\ 2 Department of Periodontology, Manipal College of Dental Sciences, Manipal Academy of Higher Education, \\ Manipal 576104, India; pratibha.pk@manipal.edu \\ 3 Schrödinger, Bengaluru, Karnataka 560086, India; sudharsan.pandiyan@schrodinger.com \\ 4 School of Pharmacy and Medical Science, University of South Australia, Adelaide, SA 5000, Australia; \\ Sanjay.Garg@unisa.edu.au \\ * Correspondence: usha.nayak@manipal.edu; Tel.: +91-820-2922482
}

Academic Editor: Derek McPhee

Received: 24 April 2018; Accepted: 3 June 2018; Published: 6 June 2018

\begin{abstract}
This study was aimed at formulating a bioabsorbable, controlled-release, nanoemulgel of Quercetin, a potent antimicrobial and anti-inflammatory agent for the treatment of periodontitis that could improve its solubility and bioavailability. Screening of components was carried out based on the solubility studies. Nanoemulsion containing cinnamon oil as the oil phase, tween 80 and Carbitol ${ }^{\circledR}$ as the surfactant-cosurfactant mixture $\left(S_{\text {mix }}\right)$ and water as the aqueous phase containing $125 \mu \mathrm{g} / 200 \mu \mathrm{L}$ of Quercetin was prepared by using spontaneous emulsification method. Nanoemulgel was prepared using $23 \% w / v$ poloxamer 407 as gel base. Comprehensive evaluation of the formulated nanoemulgel was carried out, and the optimized formulation was studied for drug release using Franz vertical diffusion cells. The formulated nanoemulgelexhibited a remarkable release of $92.4 \%$ of Quercetin at the end of $6 \mathrm{~h}$, as compared to that of pure Quercetin-loaded gel $(<3 \%$ release). The viscosity of the prepared nanoemulgel was found to be $30,647 \pm 0.32 \mathrm{cPs}$ at $37^{\circ} \mathrm{C}$. Also, molecular dynamics (MD) simulation was utilized to understand the gelation process and role of each component in the formulation. The present study revealed that the developed nanoemulgel of Quercetin could be a potential delivery system for clinical testing in periodontitis.
\end{abstract}

Keywords: nanoemulgel; periodontitis; spontaneous emulsification; antimicrobial; molecular simulation; computational formulation design

\section{Introduction}

Periodontitis is a chronic inflammatory disease affecting the supporting structures of the teeth. It is a disease of multifactorial etiology, with microbial, genetic, environmental and host factors involved. As a result, a state of chronic inflammation persists, with the release of oxygen-free radicals by the inflammatory cells, mainly the polymorphonuclear lymphocytes. Inadequate dental plaque removal results in the inflammation of gums/gingivae and their separation from the tooth surface by marginal tissue recession and deepening of the gingival sulcus resulting in periodontal pocket formation. This process is accompanied by destruction of tooth-supporting bone, thereby compromising the support of the tooth and its eventual exfoliation. This destructive process is facilitated by the enzymes 
and toxic by-products released by the periodontal pathogenic microflora, which can break down host cell membranes and extracellular matrices, to produce nutrients essential for their growth [1-5]. Periodontal disease is currently being investigated for association with a large number of systemic diseases like cardiovascular disease, rheumatoid arthritis, and diabetes [6-8].

Therapeutic management of the disease includes nonsurgical treatment of periodontal disease with scaling and root planing, systemic antibiotics, anti-inflammatory and bone regenerating agents, etc. Various antimicrobial agents have also been tested in local delivery systems, for their efficacy in the inhibition of colonization as well as in the prevention of plaque formation [9]. Non-steroidal anti-inflammatory drugs (NSAIDs) have also reportedly been used with limited success [10]. Nevertheless, orally administered drugs suffer from drawbacks due to their systemic effect and also result in lack of effective concentration of the drug at the site of action, resulting in poor patient acceptance. This necessitates the development of alternative localized delivery of drugs. Many in situ localized deliveries of drugs such as simvastatin, atorvastatin, ornidazole, levofloxacin, and flurbiprofen have been evaluated with positive results for periodontitis [11-15].

Recent studies have reported that phytochemicals have been found to be effective in the treatment of periodontitis [16]. Bioflavonoids, particularly Quercetin, have shown potential antimicrobial activity, lowering of inflammatory markers, cholesterol reduction and inhibiting bone loss. However, this data has largely been obtained from in vitro and animal studies, but data from human studies are limited. Quercetin has been found to decrease the extracellular matrix degradation, promote wound healing when tested in gingival fibroblasts, and showed excellent antibacterial properties. It also possesses anti-inflammatory effects which can be explored to restrict the inflammation in periodontitis $[17,18]$. Hence, in the present study, we attempted to formulate an in situ nanoemulgel of Quercetin based on the antimicrobial sensitivity to specific periodontal pathogens [19-21]. Despite the beneficial effects of Quercetin, its poor aqueous solubility and poor bioavailability result in limited absorption. Scientists have worked on improving the bioavailability of Quercetin using various approaches, such as nanosuspension [22], self-nano emulsifying systems [20], microemulsion [23], solid lipid nanoparticles [24], cyclodextrin complexes [25]. The combination of oils and emulsifiers enhances the absorption of Quercetin [26]. Hence, nanoemulsion could be a suitable drug delivery vehicle for the loading of Quercetin. Nanoemulsions are more beneficial than microemulsions, as they have high kinetic stability and a smaller droplet size [27]. Nanoemulsion increases the rate of absorption and eliminates variability in absorption, helps in solubilizing lipophilic drug and increases bioavailability. It allows rapid and efficient penetration of the drug moiety. These can be incorporated into the polymer solution to form in situ nanoemulgel, which provides sustained/controlled drug delivery and ease of administration, thus enhancing patient compliance.

Hence, in the present study, the advantages of nanoemulgel were exploited for the efficient delivery of Quercetin. Also, a computer-aided formulation design approach was used to understand the gelation process and role of each component in the formulation. Computer-aided formulation design approaches are the current trend in the context of dosage form development. The computational approach will not only reduce the experimental efforts, but also help in studying the mechanistic physiological behavior of the dosage form [28,29].

\section{Results and Discussion}

\subsection{Screening of Nanoemulsion Components Based on the Solubility of Quercetin}

The solubility of the drug in oil plays a major role in formulating nanoemulsion to incorporate the maximum dose and maintain the drug in solubilized state. Therefore, the components exhibiting the highest solubility were utilized in different combinations in conducting formulation trials to obtain a nanoemulsion. On the basis of the saturation solubility, the components exhibiting the highest solubility were categorized according to the order of their solubility. The order of Quercetin solubility in oils was cinnamon oil $>$ triacetin $>$ castor oil $>$ sesame oil $>$ labrafac $>$ palm oil $>$ isopropyl myristate 
$>$ migliyol. The solubility order in surfactants was labrasol $>$ tween $80>$ tween $60>$ cremophor EL $>$ span $80>$ tween 20 and cosurfactants was transcutol HP > carbitol > ethylene glycol > ethanol > capryol > lutrol $400>$ lutrol $600>$ glycerol (Refer Supplementary Materials Figures S1 and S2).

\subsection{Construction of Pseudo-Ternary Phase Diagrams}

Based on the saturation solubility study, different formulation trials were conducted using the various combinations of oil, surfactant and cosurfactant, as given in Table 1. No nanoemulsion formation was observed in the 1st (cinnamon oil, Labrasol ${ }^{\circledR}$ and Transcutol HP) and 4th set (Labrafac PG ${ }^{\circledR}$, Labrasol ${ }^{\circledR}$ and Carbitol $^{\circledR}$ ) with varying ratios of oil:S $S_{\text {mix }}$ and $S_{\text {mix }}$ alone. The 2 nd (cinnamon oil, tween 80 and $\mathrm{Carbitol}^{\circledR}$ ) and 3rd set (cinnamon oil, tween 80 and ethylene glycol) yielded nanoemulsion; however, the nanoemulsion region occupied by the 2 nd combination was greater than the $3 r d$ set. The ternary phase diagrams depict the ability of surfactant and cosurfactant to solubilize the oil phase to obtain a clear nanoemulsion. Larger nanoemulsion regions indicate maximum capability to form a nanoemulsion with the drug. Figures 1 and 2 show the ternary plots for nanoemulsions obtained using cinnamon oil, tween 80 and ethylene glycol; and cinnamon oil, tween 80 and Carbitol ${ }^{\circledR}$, respectively. In cinnamon oil, tween 80 and ethylene glycol combination, as the amount of tween 80 was increased, a larger nanoemulsion region was observed, as seen in Figure 1 with $S_{\text {mix }}$ 4:1. This may be attributed to the better surface coverage of tween 80 over the nanoemulsion droplets leading to a reduction in interfacial tension and leading to spontaneous dispersion [30]. A similar result was observed with cinnamon oil, tween 80 and Carbitol ${ }^{\circledR}$ combination. A large nanoemulsion region was observed with $S_{\text {mix }} 5: 1$. Based on the ternary plots, the 2nd set composition of cinnamon oil, tween 80 and Carbitol $^{\circledR}$ containing the $S_{\text {mix }}$ ratio of 5:1 and an oil: $S_{\text {mix }}$ ratio 1:9 were chosen for optimization. Representative formulation titration trials conducted for the $S_{\text {mix }}$ ratio 1:9 and the oil: $S_{\text {mix }}$ ratio 5:1 are shown in Table 1.

Smix $1: 1$

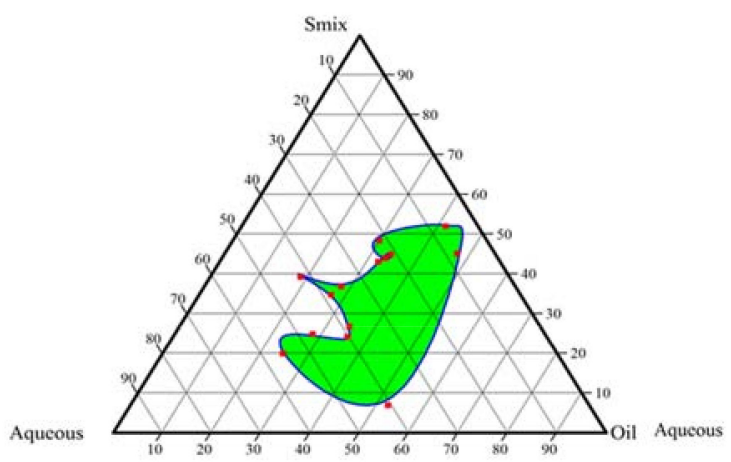

$\mathrm{Smix}=1: 4$

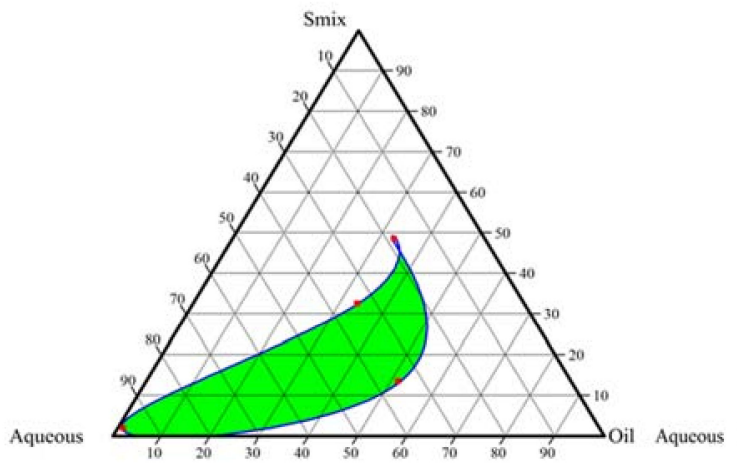

Smix 2:1

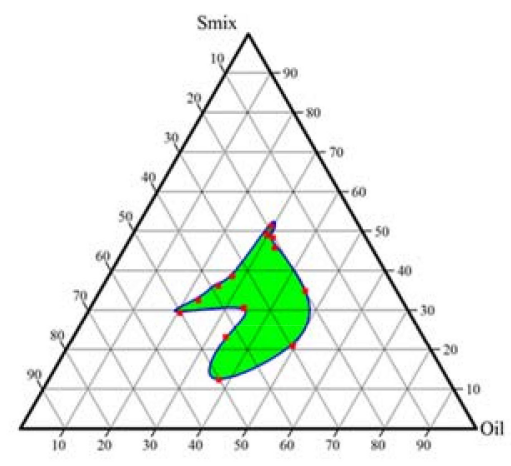

Smix $=4: 1$

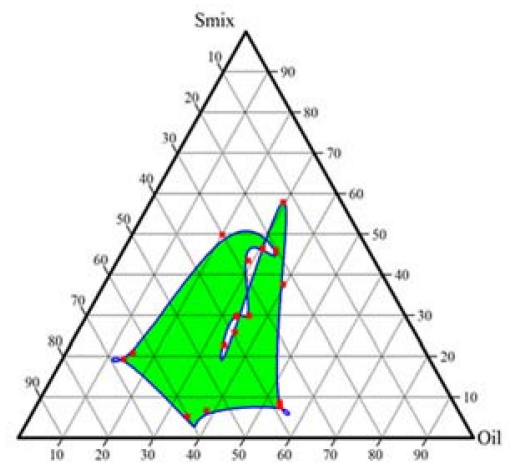

Figure 1. Ternary plots for nanoemulsions obtained using cinnamon oil, tween 80 and ethylene glycol. 
Smix $=1: 0$

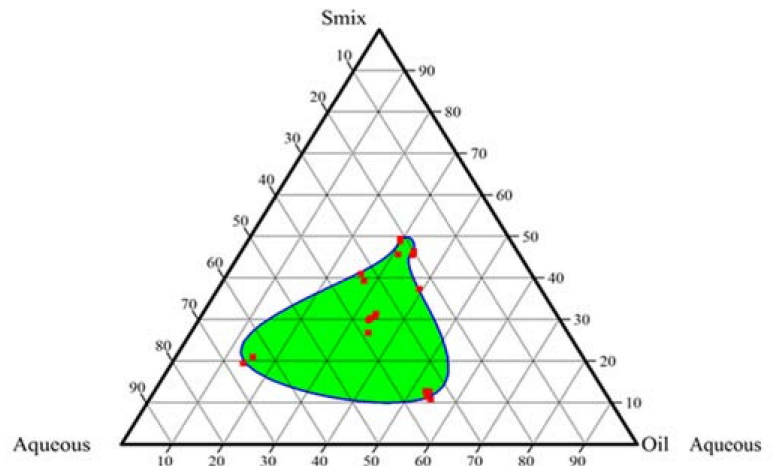

Smix $=1: 3$

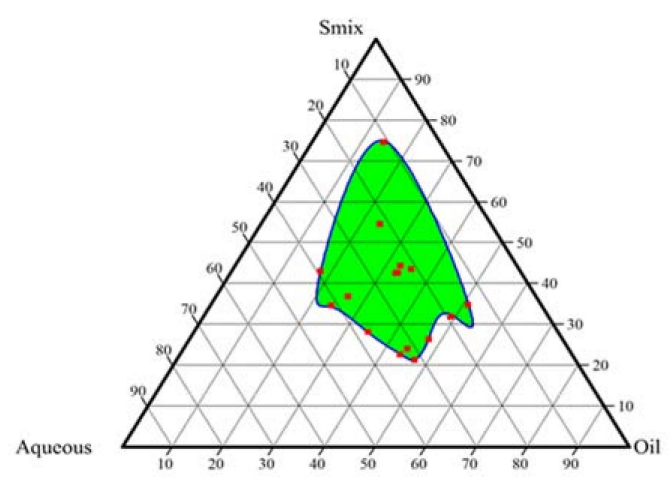

Smix $=4: 1$

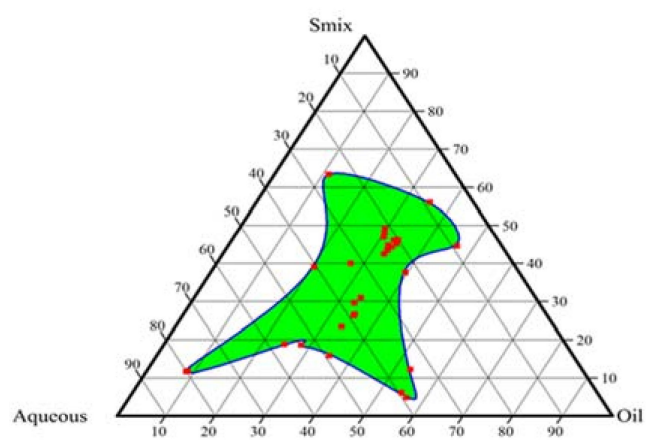

Smix $=1: 2$

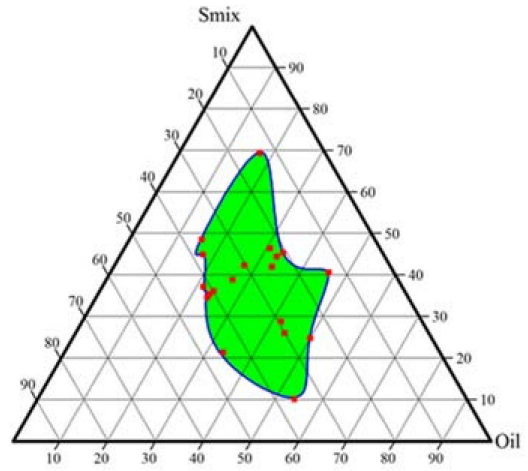

Smix $=3: 1$

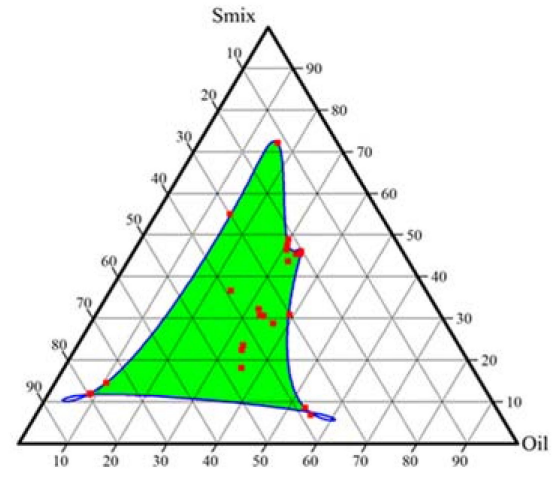

Smix $=5: 1$

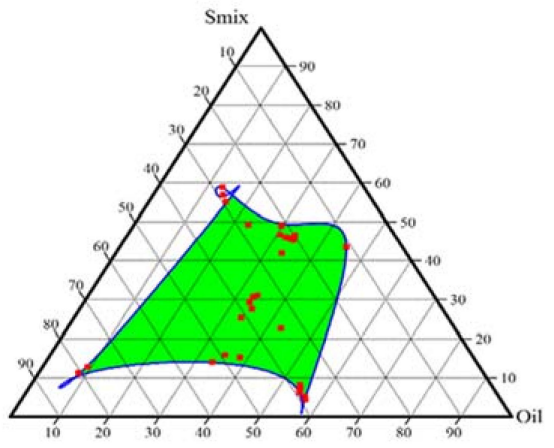

Figure 2. Ternary plots for nanoemulsions obtained using cinnamon oil, tween 80 and Carbitol ${ }^{\circledR}$.

Table 1. Formulation titration trials conducted for $S_{\text {mix }}$ ratio 1:9 (Tween 80:Carbitol ${ }^{\circledR}$ ) and 5:1 (Cinnamon oil:S $S_{\text {mix }}$ ratio).

\begin{tabular}{cccccccccc}
\hline $\begin{array}{c}\text { Oil } \\
(\mathbf{m g})\end{array}$ & $\begin{array}{c}\mathbf{S}_{\mathbf{m i x}} \\
\mathbf{( m g})\end{array}$ & $\begin{array}{c}\text { Water } \\
\mathbf{( m g )}\end{array}$ & $\begin{array}{c}\text { Water } \\
\text { Added }\end{array}$ & $\begin{array}{c}\text { Total } \\
\mathbf{( m g )}\end{array}$ & Appearance & Formulation & $\begin{array}{c}\text { Oil } \\
\mathbf{( \% )}\end{array}$ & $\begin{array}{c}\mathbf{S}_{\operatorname{mix}} \\
\mathbf{( \% )}\end{array}$ & $\begin{array}{c}\text { Water } \\
\mathbf{( \% )}\end{array}$ \\
\hline 20 & 180 & 30 & 30 & 230 & Transparent, easily flowable & Nanoemulsion & 8.69 & 78.2 & 13.04 \\
20 & 180 & 90 & 60 & 290 & Transparent, easily flowable & Nanoemulsion & 6.89 & 62.0 & 31.03 \\
20 & 180 & 190 & 100 & 390 & Transparent, easily flowable & Nanoemulsion & 5.12 & 46.15 & 48.71 \\
20 & 180 & 390 & 200 & 590 & Transparent, easily flowable & Nanoemulsion & 3.38 & 30.50 & 66.10 \\
20 & 180 & 590 & 200 & 790 & Transparent, easily flowable & Nanoemulsion & 2.53 & 22.78 & 74.68 \\
20 & 180 & 1090 & 500 & 1290 & Transparent, easily flowable & Nanoemulsion & 1.55 & 13.95 & 84.49 \\
20 & 180 & 1590 & 500 & 1790 & Transparent, easily flowable & Nanoemulsion & 1.11 & 10.05 & 88.82 \\
\hline
\end{tabular}




\subsection{Optimization of Quercetin Nanoemulsion}

Quercetin was incorporated in the nanoemulsion composition optimized based on ternary plots. The amount to be incorporated was based on Minimum Inhibitory Concentration (MIC) study. The MIC study was performed to assess the effectiveness of Quercetin against two prominent periodontal pathogens, namely Tannerella forsythia and Porphyromonas gingivalis. Based on the MIC study against the periodontal pathogens as given in Table 2, the dose of Quercetin was selected in the range of $75-125 \mu \mathrm{g} / \mathrm{mL}$. The optimized composition of nanoemulsion was $4.68 \mathrm{mg}$ Quercetin, $125 \mathrm{mg}$ cinnamon oil, $1125 \mathrm{mg}$ tween $80,225 \mathrm{mg} \mathrm{Carbitol}{ }^{\circledR}$, and $6000 \mathrm{mg}$ water. The nanoemulsion was transparent and easily flowable.

Table 2. MIC study of Quercetin against periodontal pathogens.

\begin{tabular}{ccccccccccc}
\hline $\mathrm{Q}(\boldsymbol{\mu} / \mathrm{mL})$ & $\mathbf{1 0 0}$ & $\mathbf{5 0}$ & $\mathbf{2 5}$ & $\mathbf{1 2 . 6}$ & $\mathbf{6 . 2 5}$ & $\mathbf{3 . 1 2}$ & $\mathbf{1 . 6}$ & $\mathbf{0 . 8}$ & $\mathbf{0 . 4}$ & $\mathbf{0 . 2}$ \\
\hline $\mathrm{Tf}$ & $\mathrm{S}$ & $\mathrm{S}$ & $\mathrm{R}$ & $\mathrm{R}$ & $\mathrm{R}$ & $\mathrm{R}$ & $\mathrm{R}$ & $\mathrm{R}$ & $\mathrm{R}$ & $\mathrm{R}$ \\
$\mathrm{Pg}$ & $\mathrm{S}$ & $\mathrm{R}$ & $\mathrm{R}$ & $\mathrm{R}$ & $\mathrm{R}$ & $\mathrm{R}$ & $\mathrm{R}$ & $\mathrm{R}$ & $\mathrm{R}$ & $\mathrm{R}$ \\
\hline
\end{tabular}

Note: Q-Quercetin; S-Sensitive; R—Resistant; Tf-Tannerella forsythia; Pg—Porphyromonas gingivalis.

\subsection{Thermodynamic Stability Testing of the Nanoemulsion}

A thermodynamic stability study was carried out to assess the kinetic stability of the nanoemulsion. Stress studies such as centrifugation, heating-cooling cycle, and freeze-thaw cycle were performed. The nanoemulsion was found to be stable, and no phase separation or Ostwald ripening were observed during these studies.

\subsection{Characterization Results for Nanoemulsion}

Globule size, Polydispersity Index (PDI) and zeta potential of the nanoemulsion was determined at 10 times and 100 times dilution. Consistent results were observed after both the dilutions. The results of a few selected batches are shown in Table 3. As the amount of oil increased, there was an increase in the globule size [31], whereas zeta potential was found to increase with an increase in the quantity of $\mathrm{S}_{\mathrm{mix}}$, as the charge on the surface of globules is governed by the presence of surfactants which results in better stabilization of the nanoemulsion. The negative sign of zeta potential may be due to the presence of anionic groups of fatty acids in the cinnamon oil, tween 80 and -OH group of Carbitol ${ }^{\circledR}$. The higher the zeta potential, the higher the stability of the nanoemulsion in general. However, as the nanoemulsion was incorporated in to the gel, the mobility of globules is restricted, and therefore no significant influence of zeta potential can be observed. A decrease in the amount of $S_{\text {mix }}$ was found to increase the globule size. This may be attributed to the fact that a higher amount of surfactant is required to stabilize and produce fine droplets of nanoemulsion [30,32]. There was no significant difference in the PDI of nanoemulsions between the batches $(p>0.1)$.

Table 3. Globule size, Polydispersity Index (PDI) and Zeta potential of nanoemulsion comprising of tween 80: Carbitol $^{\circledR}$ as $S_{\text {mix }}$ and cinnamon oil.

\begin{tabular}{ccccc}
\hline Sr. No. & Sample Name & Z Average Size $(\mathbf{n m})$ & PDI & Zeta Potential $(\mathbf{m V})$ \\
\hline 1 & Smix ratio 5:1 Oil: Smix 1:7 & $153.51 \pm 8.23$ & $0.60 \pm 0.03$ & $-3.03 \pm 0.02$ \\
2 & Smix ratio 5:1 Oil: Smix 1:9 & $138.90 \pm 10.14$ & $0.56 \pm 0.04$ & $-3.58 \pm 0.01$ \\
3 & Smix ratio 4:1 Oil: Smix 1:7 & $136.05 \pm 10.17$ & $0.48 \pm 0.07$ & $-9.20 \pm 0.02$ \\
4 & Smix ratio 4:1 Oil: Smix 1:9 & $125.60 \pm 9.42$ & $0.53 \pm 0.10$ & $-12.10 \pm 0.07$ \\
5 & Smix ratio 3:1 Oil: Smix 1:7 & $115.20 \pm 8.31$ & $0.47 \pm 0.05$ & $-3.16 \pm 0.02$ \\
6 & Smix ratio 3:1 Oil: Smix 1:9 & $104.33 \pm 6.28$ & $0.39 \pm 0.12$ & $-4.03 \pm 0.04$ \\
\hline
\end{tabular}




\subsection{Surface Morphology of Nanoemulsion Using TEM}

To study the morphology and distribution of nanoemulsion, transmission electron microscopy photomicrographs were taken, as shown in Figure 3. It was observed that the globule size was less than $200 \mathrm{~nm}$, and the globules were discrete and spherical without any aggregation.
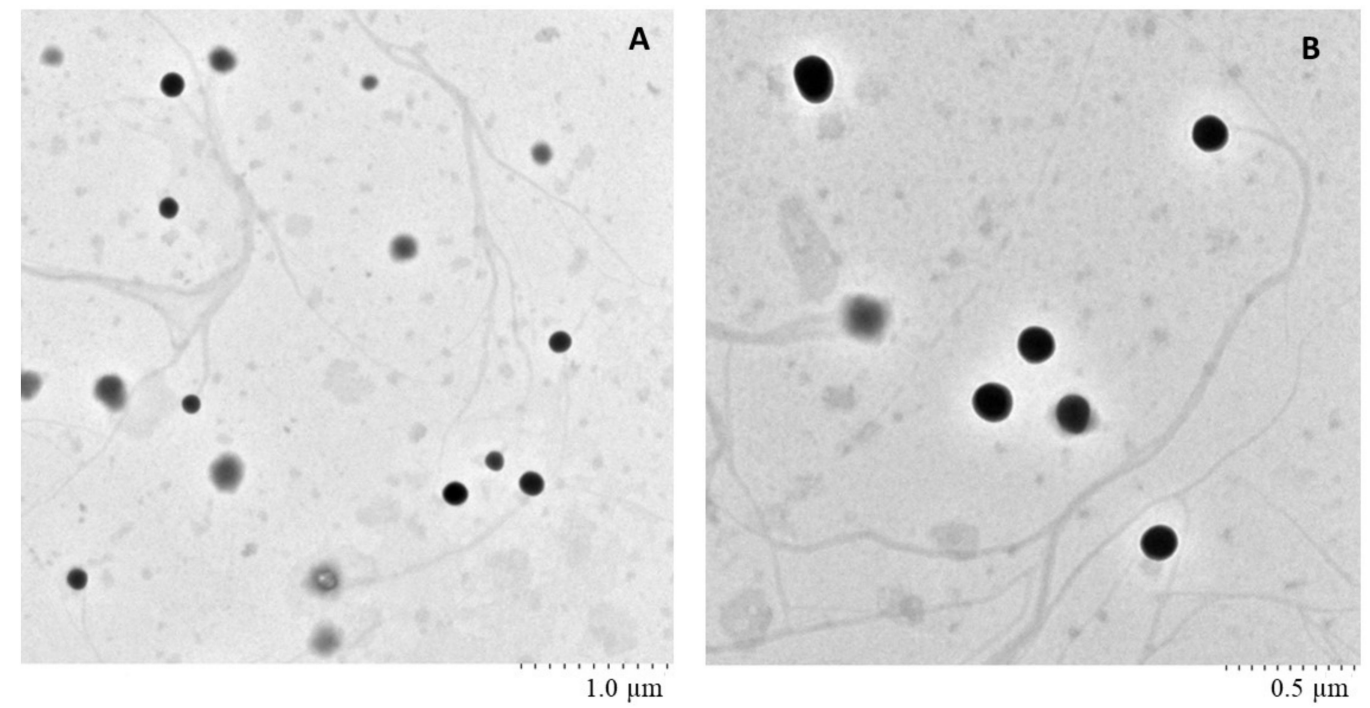

Figure 3. TEM images of nanoemulsion at different magnification (A) scale $1.0 \mu \mathrm{m}$, (B) scale $0.5 \mu \mathrm{m}$.

\subsection{Preparation of Nanoemulgel}

Various FDA Inactive Ingredient Guide (IIG)-approved polymers were investigated for the in situ gelation process. Poloxamer 188 and poloxamer 407 solutions were prepared separately in concentrations ranging from $15 \% w / v$ to $25 \% w / v$ and checked for in situ gelation at $37^{\circ} \mathrm{C}$. Xanthan gum was tested for in situ gel formation at a concentration ranging from $0.05-0.1 \% w / v$ to $1-3 \% w / v$ utilizing calcium chloride dihydrate and trisodium citrate as crosslinking agents. Gellan gum solutions were prepared at concentration ranges of $0.3-0.7 \% w / v$. Carbopol 934P was tested for gelation at a concentration range of $0.5 \% w / v$ in combination with $25 \% w / v$ of poloxamer 407 solution. However, no gel formation was observed in the case of xanthan gum, gellan gum and carbopol $934 \mathrm{P}$ at $37^{\circ} \mathrm{C}$ at any of the concentrations. Hence the polymer poloxamer 407 at a concentration of $23 \% w / v$ was chosen as a suitable gelling agent for in situ gel formation.

Based on the ternary plots, $S_{\text {mix }}$ ratio 5:1 and oil: $S_{\text {mix }}$ ratio 1:9 was selected as an optimized formula. The aqueous media, water was replaced with the incorporation of an aqueous solution of gel base $23 \% w / v$ poloxamer 407 while preparing nanoemulgel. The optimized composition of nanoemulgel was $4.68 \mathrm{mg}$ Quercetin, $125 \mathrm{mg}$ cinnamon oil, $1125 \mathrm{mg}$ tween 80, $225 \mathrm{mg}$ Carbitol $^{\circledR}$, $1380 \mathrm{mg}$ poloxamer $407,6000 \mathrm{mg}$ water. $200 \mu \mathrm{L}$ is the estimated volume that can be instilled inside the periodontal pocket. Accordingly, every $200 \mu \mathrm{L}$ contained a specified dose, $125 \mu \mathrm{g}$ of Quercetin.

\subsection{Characterization Results of Nanoemulgel}

In the sol-gel transition study, it was observed that in situ gel formation occurred in $53 \pm 2 \mathrm{~s}$ at $37^{\circ} \mathrm{C}$. The nanoemulsion passed the syringeability test. The $\mathrm{pH}$ of Quercetin nanoemulgel was found to be $6.34 \pm 0.5$ measured using a $\mathrm{pH}$ paper which was in accordance with the $\mathrm{pH}$ of the gingival crevicular fluid indicating suitability for drug delivery into the periodontal pocket. The viscosity of the nanoemulgel was found to be low at room temperature, and a drastic increase was observed at body temperature with respect to the gelation capacity of the polymer. Viscosity was $408.3 \pm 0.5 \mathrm{cPs}$ at $26 \pm 0.5^{\circ} \mathrm{C}$ and $30,647.5 \pm 0.3 \mathrm{cPs}$ at $37 \pm 0.5^{\circ} \mathrm{C}$, demonstrating the sol-gel nature of the formulation. 
The drug content of the prepared nanoemulgel was found to be $99.5 \pm 0.02 \%$. There was no loss of drug during the preparation of nanoemulgel $[33,34]$.

\subsection{In Vitro Diffusion of Quercetin from Nanoemulgel}

The diffusion study of optimized nanoemulgel was carried out in comparison to a gel incorporated with pure Quercetin. The \% drug diffused from nanoemulgel was sustained and found to be $92.4 \pm 4.6 \%$ at the end of $6 \mathrm{~h}$. However, the drug release from the Quercetin-loaded gel (comprising of $23 \%$ poloxamer 407 gel loaded with Quercetin) was much less ( $<3 \%$ drug at the end of $6 \mathrm{~h}$ ), which may be due to the poor solubility of the drug in an aqueous gel base. The higher surface area due to smaller globule size in nanoemulsion permitted higher drug release from nanoemulgel. The sustained drug release from the in situ gel may be due to the matrix structure of the gel, which may be the result of increased micelles within the gel structure. The greater number of cross-links between neighboring micelles results in higher viscosity and a lower rate of drug release [35] (Figure 4). A zero-order release pattern was observed with the formulation $\left(R^{2}=0.9238\right)$ (Figure 5).

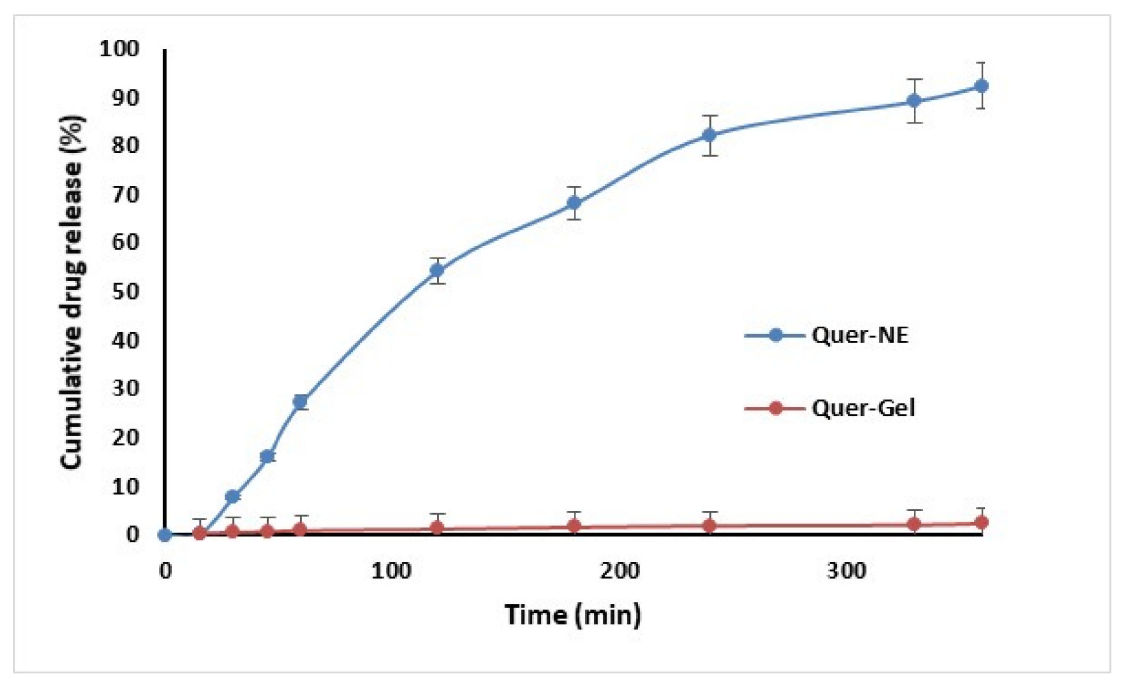

Figure 4. In vitro drug diffusion profile.

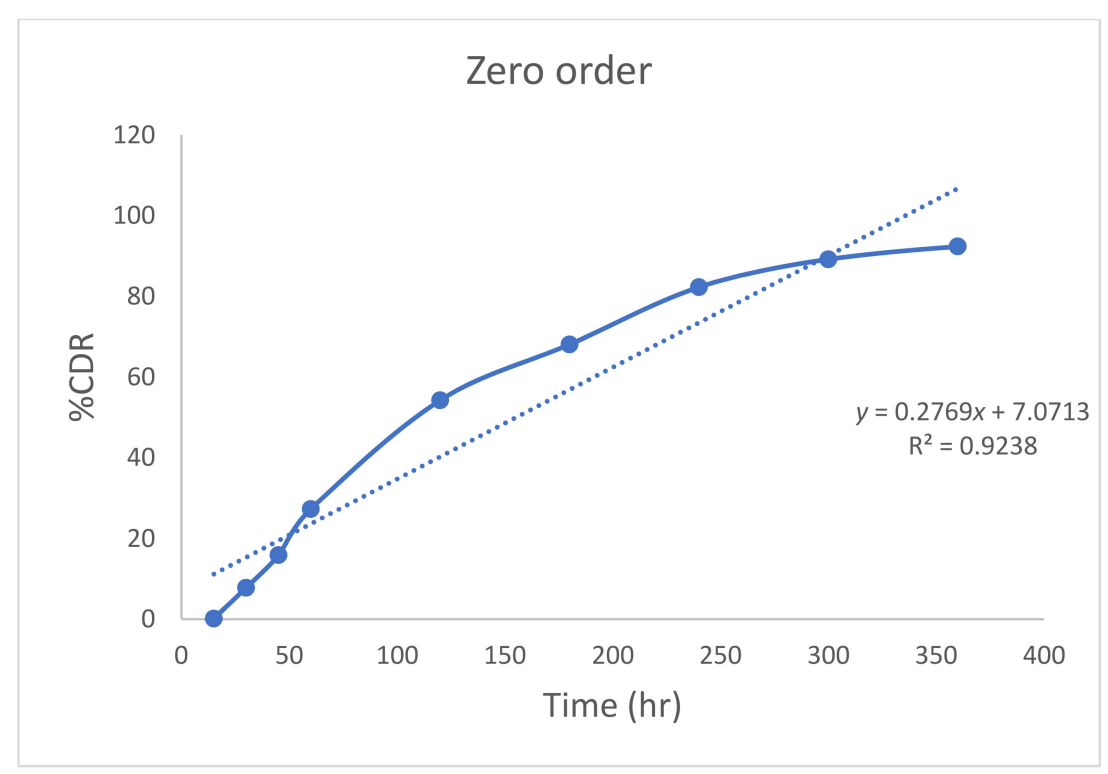

Figure 5. Zero-order release kinetics for nanoemulgel. 


\subsection{Stability Study Results}

The formulated nanoemulgel exhibited good physical stability over a storage period of 3 months (90 days). The samples had a pale yellow-colored appearance with a pH ranging from 6 to 6.5. The drug content was more than $97 \pm 1.5 \%$ for all the time points. The stability data is given in Table 4 .

Table 4. Stability assessment data of Quercetin nanoemulgel.

\begin{tabular}{cccc}
\hline Days & Drug Content & $\mathbf{p H}$ & Colour \\
\hline 0 & $99.98 \pm 0.24$ & 6.5 & Pale yellow \\
5 & $99.72 \pm 0.40$ & 6.5 & Pale yellow \\
30 & $98.98 \pm 0.78$ & 6.5 & Pale yellow \\
60 & $98.12 \pm 1.1$ & 6.5 & Pale yellow \\
90 & $97.0 \pm 1.5$ & 6.5 & Pale yellow \\
\hline
\end{tabular}

\subsection{Results of Molecular Dynamic Simulations}

The physical properties of the systems at $275 \mathrm{~K}\left(1.85^{\circ} \mathrm{C}\right)$ and $313 \mathrm{~K}\left(39.85^{\circ} \mathrm{C}\right)$ are presented in Table 5. These property differences at the molecular level provide an insight into the gel phase at $313 \mathrm{~K}$. It has already been reported in the literature that the self-diffusion coefficient of water at $275 \mathrm{~K}$ is $\sim 1.2765 \times 10^{-9} \mathrm{~m}^{2} / \mathrm{s}$ and the same at $313 \mathrm{~K}$ is $3.222 \times 10^{-9} \mathrm{~m}^{2} / \mathrm{s}$ [36]. It is evident from the table that the water is more or less in its bulk phase at $275 \mathrm{~K}$, as the formulation components are solvated inside the water phase. On the other hand, the negative difference between the bulk water diffusion coefficient and the same of water in the formulation at $313 \mathrm{~K}$ proves slow dynamics of the water (Figure 6). The increase in the number of hydrogen bonds between the formulation components and the water molecules also indicates the increased interaction between the components. Figure 7 exhibits the specific volume change as a function of temperature for the entire formulation mixture. It is evident from the plot that there is a sol to gel phase transformation at $\sim 290 \mathrm{~K}$. This is in very good agreement with the experimental gelation temperature.
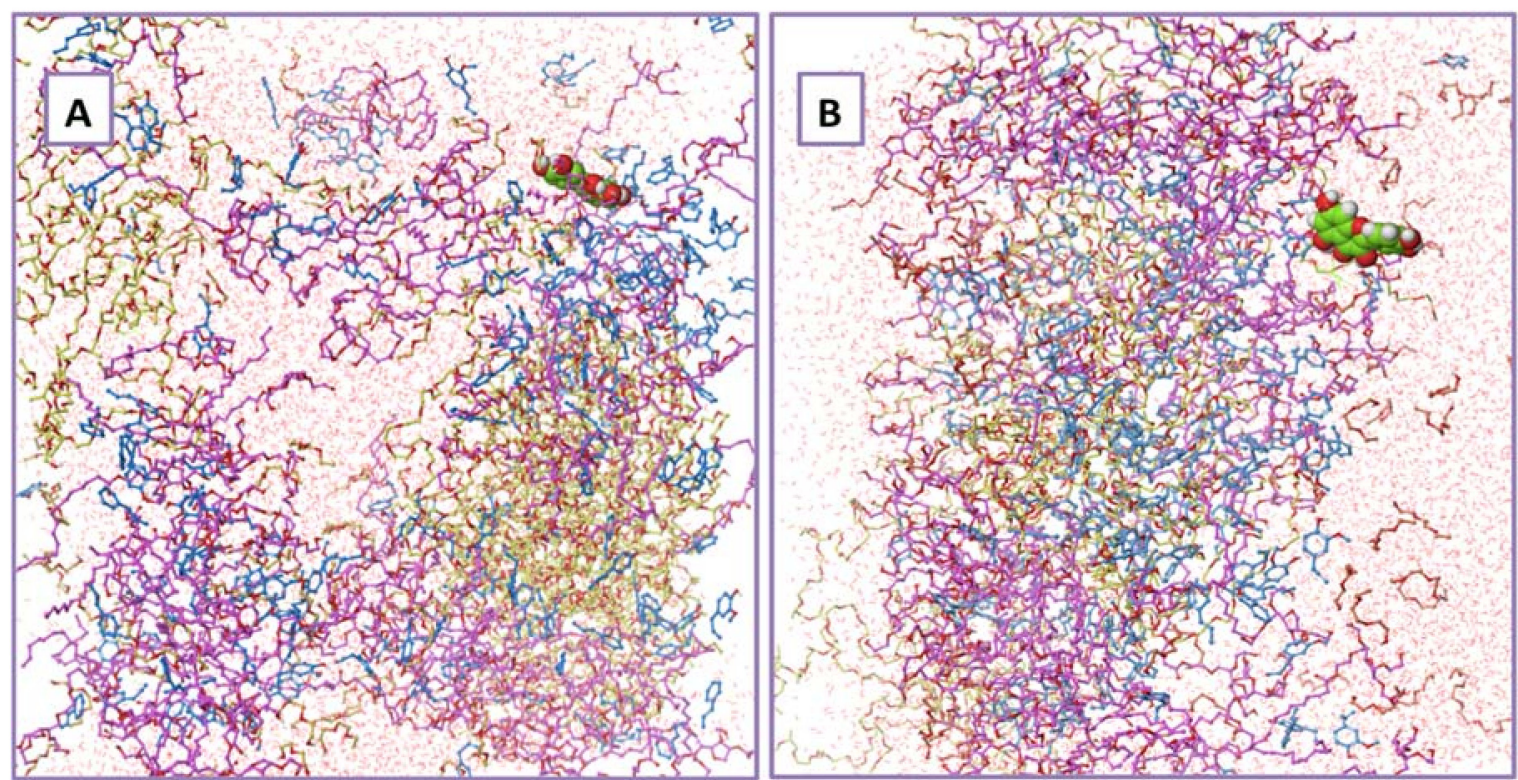

Figure 6. Formation of gel inside the water for the formulation used in this study. (A) The formulation components at $275 \mathrm{~K}$; and (B) the formulation components at $313 \mathrm{~K}$. Quercetin is represented in the form of a CPK model with green color, whereas the cinnamon oil is represented in cyan color, Carbitol ${ }^{\circledR}$ is represented in pink color, tween 80 is represented in brown color and poloxamer 407 is represented with yellow color ball and tube. 


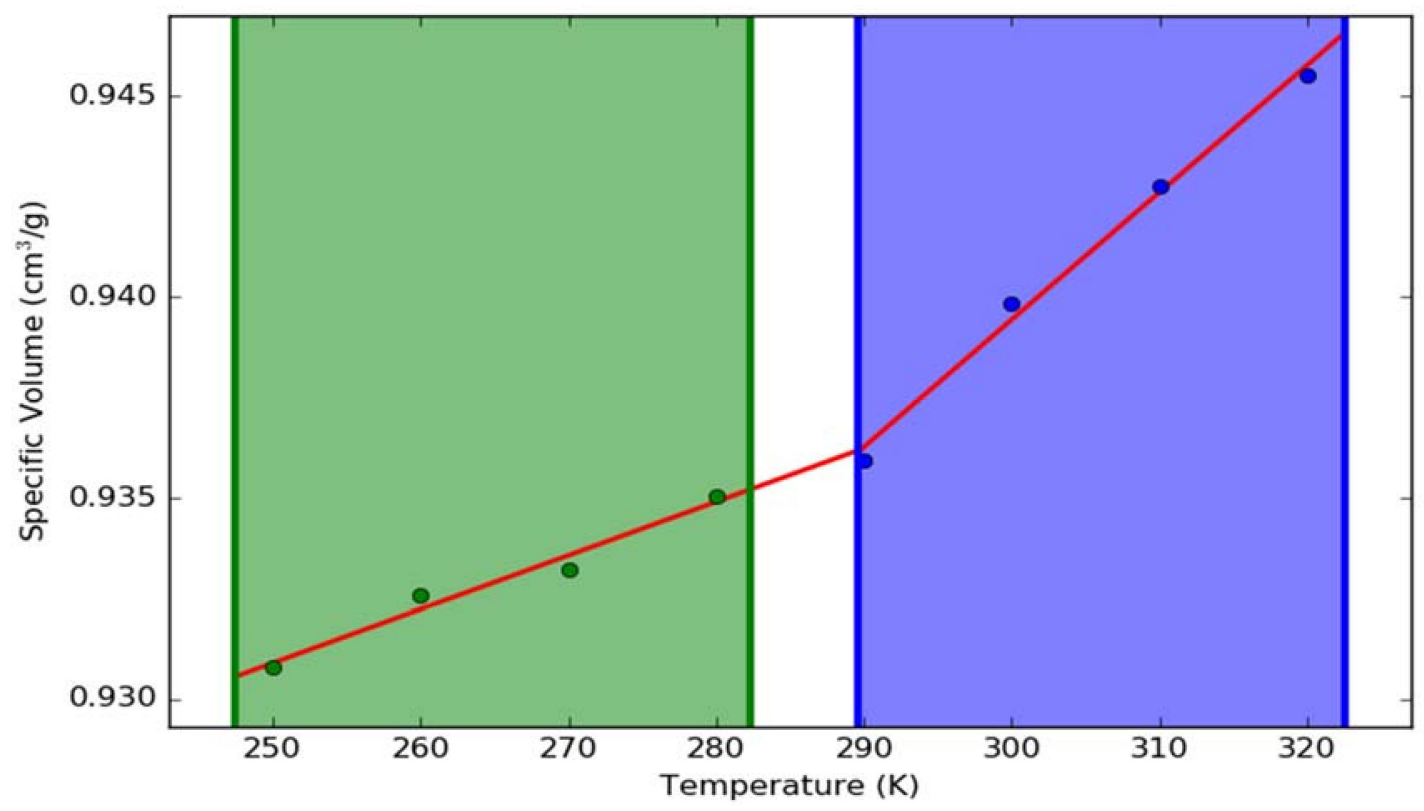

Figure 7. Effect of temperature on the specific volume of the simulation box containing formulation components and water.

Table 5. Physical properties of the formulation in both sol at $275 \mathrm{~K}\left(1.85^{\circ} \mathrm{C}\right)$ and gel phase at $313 \mathrm{~K}\left(39.85^{\circ} \mathrm{C}\right)$.

\begin{tabular}{ccc}
\hline Property & At $275 \mathrm{~K}$ & At 313 K \\
\hline Density & $1065 \pm 4 \mathrm{~kg} / \mathrm{m}^{3}$ & $1060 \pm 6 \mathrm{~kg} / \mathrm{m}^{3}$ \\
No. of Hydrogen bonds between formulation components and solvent & $991 \pm 20$ & $1200 \pm 21$ \\
Diffusion coefficient of solvent & $1.2504 \times 10^{-9} \mathrm{~m}^{2} / \mathrm{s}$ & $2.8332 \times 10^{-9} \mathrm{~m}^{2} / \mathrm{s}$ \\
Diffusion coefficient of formulation components & $1.0746 \times 10^{-10} \mathrm{~m}^{2} / \mathrm{s}$ & $2.4066 \times 10^{-10} \mathrm{~m}^{2} / \mathrm{s}$ \\
Radii of gyration of Poloxamer 407 molecules & $29.45 \pm 2.2$ & $31.72 \pm 4.3$ \\
\hline
\end{tabular}

\section{Materials and Methods}

\subsection{Materials}

Quercetin was purchased from Himedia, Mumbai. Poloxamer 407, Poloxamer 188 were purchased from Sigma Aldrich, Bangalore, India. Labrafac $\mathrm{PG}^{\circledR}$, Labrasol ${ }^{\circledR}$, Carbitol ${ }^{\circledR}$, Transcutol $\mathrm{HP}^{\circledR}$ and Capryol $90^{\circledR}$ were obtained as gift samples from Gatte Fosse, Mumbai, India. Cremophor EL ${ }^{\circledR}$, Lutrol E400, Carbopol 934P, and Lutrol E600 were obtained as gift samples from BASF Corporation, Mumbai, India. Xanthan gum and Gellan gum were purchased from Triveni Chemicals, Vapi, Gujarat, India. Cinnamon oil and Palm oil were purchased from Genuine Chemical Co., Mumbai. Triacetin, Isopropyl myristate and Castor oil was from Himedia Laboratories Pvt. Ltd., Mumbai, India. Sesame oil was from National Chemicals, Gujarat, India. Migliyol was from Peter Cremer, Hamburg, Germany. Tween 80 and Tween 60 were purchased from Nice chemicals Pvt. Ltd., Kochi and Sisco Research Laboratories Pvt. Ltd., Mumbai, India. Tween 20 and Glycerol were from Merck Specialities Pvt. Ltd., Mumbai, India respectively. Span 80 was from Suvidhinath Laboratories, Baroda. Ethylene glycol was procured from Loba Chemie Pvt. Ltd., Mumbai, India. All other chemicals and reagents were of laboratory grade.

\subsection{Methods}

\subsubsection{Screening of Nanoemulsion Components}

Screening of the components was carried out based on the saturation solubility of Quercetin in various oils, surfactants, and cosurfactants. The study was carried out by dissolving the excess amount of the drug in $1 \mathrm{~mL}$ of oil, surfactant, and cosurfactant respectively. The samples were placed in a water bath shaker (Remi Sales and Engineering Ltd., Mumbai, India) at $37^{\circ} \mathrm{C}$ for $72 \mathrm{~h}$. After $72 \mathrm{~h}$, the samples 
were centrifuged at 10,000 rpm for $5 \mathrm{~min}$ (Tarsons, West Bengal, India) and the supernatants were filtered through membrane filters $(0.45 \mu \mathrm{m}$, Merck Millipore, Burlington, MA, USA), diluted with methanol and analyzed by UV spectrophotometry at $269.2 \mathrm{~nm}[35,37]$. The standard plot is shown in Figure 8.
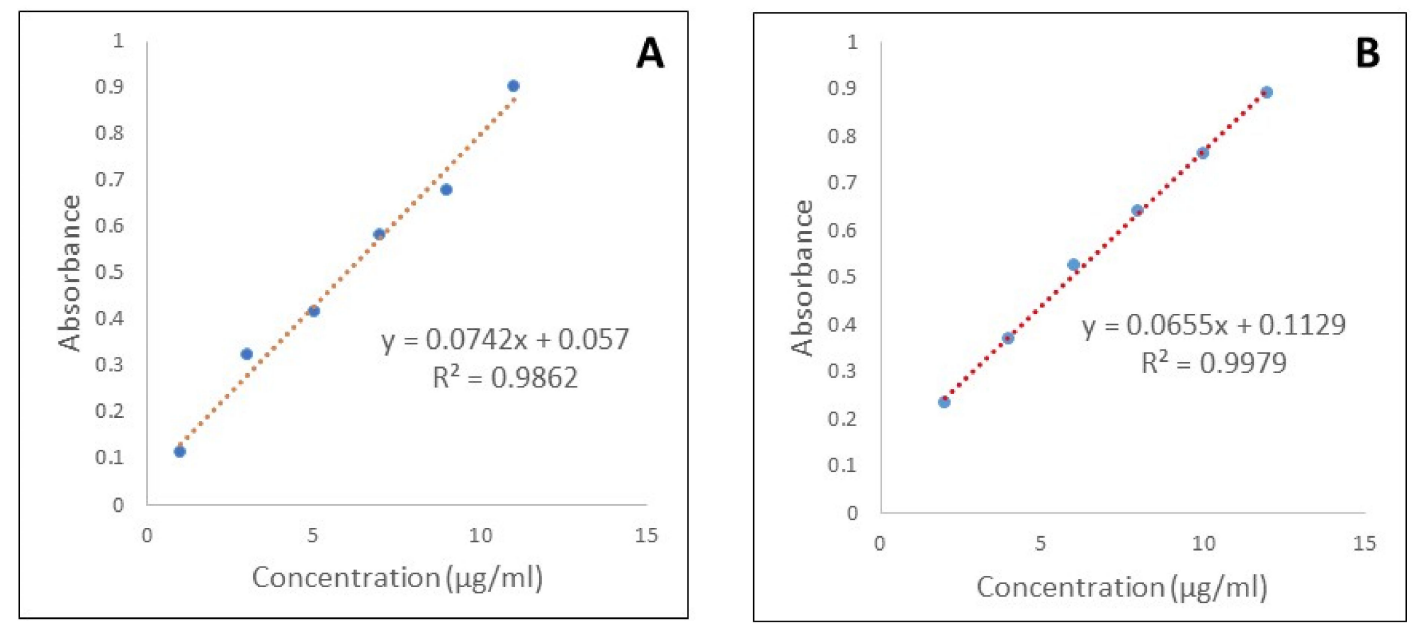

Figure 8. Calibration curve of Quercetin in (A) methanol, and (B) phosphate buffer pH 7.4.

\subsubsection{Construction of Pseudo-Ternary Phase Diagrams}

On the basis of the saturation solubility results, cinnamon oil and Labrafac $\mathrm{PG}^{\circledR}$ as the oil phase, tween 80 and Labrasol ${ }^{\circledR}$ as a surfactant, and Transcutol HP, ethylene glycol and Carbitol ${ }^{\circledR}$ as cosurfactant were selected. The nanoemulsion was prepared using a spontaneous emulsification method. The formulation was categorized based on the appearance as given in Table 6. Different combinations of oil, surfactant, and cosurfactant were attempted (see Supplementary Materials Table S1). Varying ratios of surfactant-cosurfactant $\left(S_{\mathrm{mix}}\right)$ and oil to $S_{\mathrm{mix}}$ were taken, and a specified quantity of water was added by aqueous titration method. The percentage of each component was calculated in the ratios that yielded nanoemulsion, and ternary plots were constructed accordingly using CHEMIX School 3.6 software (Arne Standnes, Norway). The ratios which generated plots that occupied the maximum nanoemulsion region were chosen for further optimization.

Table 6. Categorization criteria.

\begin{tabular}{cc}
\hline Appearance & Attributed Formulation \\
\hline Transparent and easily flowable & Nanoemulsion \\
Transparent and difficult to flow & Nanoemulgel \\
Milky/Cloudy and easily flowable & Emulsion \\
Milky/Cloudy and difficult to flow & Emulgel \\
\hline
\end{tabular}

\subsubsection{Preparation of Quercetin Nanoemulsion}

Based on the region occupied in the pseudo-ternary phase diagrams, the optimum ratios of oil, surfactant, and cosurfactant were chosen. Quercetin was incorporated into the mix to obtain nanoemulsion. The dose of the formulation was selected according to the Minimum Inhibitory Concentration (MIC). MIC of the Quercetin was determined against two prominent pathogens, namely Porphyromonas gingivalis and Tannerella forsythia, by disc diffusion method. The study was carried out in Maratha Mandal Dental College, Belgaum, Karnataka, India as per the procedure mentioned by Patil et al. [38]. 


\subsubsection{Thermodynamic Stability Testing of the Nanoemulsion}

The optimized nanoemulsion was subjected to centrifugation at $3500 \mathrm{rpm}$ for $30 \mathrm{~min}$ and observed for cracking, phase separation or any other physical changes. The effect of temperature on the stability of nanoemulsion was observed at different storage temperatures by subjecting to the heating-cooling cycle. The nanoemulsion was stored at $4{ }^{\circ} \mathrm{C}$ and $45^{\circ} \mathrm{C}$ for not less than $48 \mathrm{~h}$ for six cycles and observed for physical stability. The nanoemulsion was also subjected to freeze-thaw cycle at $-21^{\circ} \mathrm{C}$ and $+25^{\circ} \mathrm{C}$ with storage of not less than $48 \mathrm{~h}$ and observed for physical changes [31].

\subsubsection{Globule Size, Polydispersity Index (PDI) and Zeta Potential}

The mean globule size and size distribution of nanoemulsion, polydispersity index (PDI) and zeta potential were determined using Malvern Zeta Sizer (Nano ZS, Malvern, UK). The measurements were carried out at $25^{\circ} \mathrm{C}$ by dynamic light scattering technique. The zeta potential was measured by laser Doppler velocimetry and phase analysis light scattering technique. $100 \mu \mathrm{L}$ of nanoemulsion was taken and diluted with Milli-Q water to yield 10 times and 100 times dilution. The diluted samples were subjected to particle size and zeta potential analysis.

\subsubsection{Transmission Electron Microscopy (TEM)}

Transmission Electron Microscopy (TEM) of nanoemulsion was studied using Hitachi H-7650, Tokyo, Japan. The nanoemulsion was stained with uranyl acetate and dried over copper grids. The grid was examined under TEM.

\subsubsection{Preparation of Nanoemulgel}

Screening of various polymers such as xanthan gum, gellan gum, carbopol 934P, poloxamer 188 and poloxamer 407 was attempted for the in situ gelation property and polymer showing the optimum gelation time within $1 \mathrm{~min}$ was chosen as the appropriate gelling agent. Initially, polymeric solutions were prepared in water at different concentrations. The solutions were stored at $2-8{ }^{\circ} \mathrm{C}$ to ensure complete miscibility. The drug Quercetin was dissolved in oil:S $S_{\text {mix }}$ to obtain a mixture. This mixture was added dropwise to the polymeric solution or the sol system (instead of the aqueous phase in nanoemulsion) with continuous stirring to ensure the homogenous mixing of the oil phase in polymeric solution to form a nanoemulgel and stored at $2-8^{\circ} \mathrm{C}$.

\subsubsection{Characterization of Nanoemulgel}

The prepared nanoemulgel was evaluated for gelation/gelling time, syringeability, $\mathrm{pH}$, viscosity and drug content.

- Sol-gel transition and syringeability

The nanoemulgel was observed for in situ gelation or sol-gel transition by the test-tube inverting method as per Srivastava et al. with slight modification [33]. $5 \mathrm{~mL}$ of sol stored at $2-8{ }^{\circ} \mathrm{C}$ was taken in a test tube, immersed in a water bath (Remi Equipment Ltd., Bangalore, India) maintained at a temperature of $37^{\circ} \mathrm{C}$. The sample was observed for gelation by tilting the test tubes at $90^{\circ}$. Gelation was said to have occurred when the meniscus would no longer move upon tilting and the time taken to gel was recorded. For testing syringeability, nanoemulsion stored at $2-8{ }^{\circ} \mathrm{C}$ was filled into a $1 \mathrm{~mL}$ syringe with a 22 gauge needle, and gentle force was applied by pressing the piston. The ease of syringeability was observed visually.

- Drug content

For determining the drug content, $10 \mathrm{mg}$ of the Quercetin nanoemulgel formulation was weighed and dissolved in phosphate buffer $\mathrm{pH}$ 7.4. The solution was filtered using Whatman filter paper (No. 41) and suitably diluted. The absorbance of the resulting solution was measured by UV spectrophotometry (UV-160 Shimadzu Corporation, Kyoto, Japan) at $269.2 \mathrm{~nm}$ and the drug content was determined. 
- $\mathrm{pH}$ measurement

The $\mathrm{pH}$ of the nanoemulgel was read using a $\mathrm{pH}$ paper owing to the consistency of the formulation.

- Viscosity determination

The viscosity was determined using Brookfield DV III ultra-programmable rheometer (Brookfield Engineering Laboratories, Middleboro, MA, USA). The viscosity of Quercetin nanoemulgel was measured at $26^{\circ} \mathrm{C}$ and $37^{\circ} \mathrm{C}$, respectively. The instrument was calibrated using spindle 40 with viscosity standard fluid prior to the sample measurements.

\subsubsection{In Vitro Diffusion Study and Release Kinetics}

The in vitro drug diffusion study was performed using Franz vertical diffusion cells (Orchid Scientific \& Innovative India Pvt. Ltd., Maharashtra, India). The receptor compartment was filled with phosphate buffer $\mathrm{pH} 7.4$ solution and was kept in contact with the dialysis sac (MW 6000-8000 cut-offs, Sigma Aldrich, Saint Louis, MO, USA). The semipermeable membrane was firmly sandwiched between the donor and the receptor compartments. $200 \mu \mathrm{L}$ of Quercetin nanoemulgel was placed on the semipermeable membrane. $20 \mathrm{~mL}$ phosphate buffer $\mathrm{pH} 7.4$ was placed in receptor compartment. The Franz diffusion cell apparatus was integrated with a temperature regulating water bath to maintain a temperature of $37^{\circ} \mathrm{C}$ during the diffusion study. The rpm was set at 500 during the process, and $500 \mu \mathrm{L}$ sample aliquots were withdrawn at regular time intervals. The samples were analyzed using UV spectrophotometry at $269.2 \mathrm{~nm}$. Various mathematical models were used to describe the release kinetics such as zero-order, first-order, the Higuchi and the Korse-Meyer Peppas models [39].

\subsubsection{Stability Study}

Quercetin nanoemulgels were subjected to stability study as per ICH guidelines. The samples were stored in amber-colored crimped glass vials at $25{ }^{\circ} \mathrm{C} \pm 2{ }^{\circ} \mathrm{C} / 60 \% \mathrm{RH} \pm 5 \% \mathrm{RH}$ in stability chambers (Thermolab, Mumbai, India). The control samples were stored at refrigeration temperature $\left(2-8{ }^{\circ} \mathrm{C}\right)$. The samples were evaluated at specified time intervals for their appearance, $\mathrm{pH}$ and drug content.

\subsubsection{Molecular Dynamics (MD) Simulations}

Molecular dynamics simulations mimicking both the solution and gel phase was carried out using Schrödinger-Materials Science Suite (MS-Suite) version 2018-1. The representative stoichiometric ratio of all the components in the formulation was packed as an amorphous system inside a simulation box using disordered system builder within the framework of MS-Suite (See Table 7 for the component details). The following material relaxation protocol was used to build an equilibrated sample at necessary temperatures. Brownian dynamics (BD) for 10 ps at $10 \mathrm{~K}$ under NVT conditions followed by 100 ps BD at $100 \mathrm{~K}$ under NPT ensemble. These BD simulations allowed the systems to naturally evolve output of packing effects and achieve the force field defined Van der Waals volume. Subsequently, a 100 ps MD simulations were carried out under NPT conditions using an anisotropic pressure coupling at $300 \mathrm{~K}$. Finally, a $1200 \mathrm{ps}$ of MD simulation was carried out either at $275 \mathrm{~K}$ or $313 \mathrm{~K}$ under NPT conditions.

Table 7. Chemical composition of the formulation in MD simulations.

\begin{tabular}{cccc}
\hline Component & No. of Molecules & Molecular Mass & Composition in mg \\
\hline Cinnamon Oil & 34 & 282.38 & 125.00 \\
Quercetin & 1 & 302.24 & 4.68 \\
Tween 80 & 55 & 1310.00 & 1125.00 \\
Carbitol $^{\circledR}$ & 108 & 134.17 & 225.00 \\
Poloxamer $407_{\text {Water }}^{3}$ & 10,000 & $31,057.17$ & 1380.00 \\
& & 18.01 & 6000 \\
\hline
\end{tabular}


The well-equilibrated samples at $275 \mathrm{~K}$ and $313 \mathrm{~K}$ were chosen for the production run of $100 \mathrm{ns,}$ and the trajectory was recorded at every 100 ps time interval. Unless otherwise mentioned, the rest of the parameters were set to default values in the multistage workflow of MS-Suite. The following analysis was carried out in the final 800 frames of the production run. To calculate the effect of temperature on the gelation process, a separate MD simulation protocol was used under the thermophysical properties workflow of MS-Suite. The initial and final temperature range was set to 250 , and $320 \mathrm{~K}$ with the step values of $10 \mathrm{~K} .10 \mathrm{~ns}$ simulation with 3 individual systems were carried out to get the specific volume of the system.

\section{Conclusions}

The developed nanoemulgel of Quercetin using cinnamon oil, tween 80, Carbitol ${ }^{\circledR}$ and poloxamer 407 exhibited good physical characteristics, stability, sol-gel transition, and syringeability. MD simulation showed specific volume change in the formulation mixture as a function of temperature. It was evident from the computational study that there is a sol to gel phase transformation. Thus, in vitro studies proved that the nanoemulgel of Quercetin formulation could be successfully used in periodontitis. However, the preclinical and clinical efficacy of the formulation needs to be established in vivo.

Supplementary Materials: The following are available online. Figure S1: Saturation solubility profile of Qquercetin in various oils, Figure S2: Saturation solubility profile of Qquercetin in various surfactants and cosurfactants, Table S1: Composition of various formulation trials.

Author Contributions: U.Y.N., P.G. and S.G. conceived and designed the experiments. G.C.A. and C.M. performed the experiments. S.P. assisted in computational studies. G.C.A. and R.N. analyzed the data and wrote the paper. U.Y.N., P.G. and S.G. revised the paper.

Funding: This research received no external funding.

Acknowledgments: The authors are thankful to Kishore Bhat, Maratha Mandal Dental College, Belgaum for performing the MIC study and Pritesh Bhat, Schrödinger, Bengaluru for helping in computational studies. The authors would like to express their sincere gratitude to Gatte Fosse and BASF Corporation, Mumbai, India for providing gift samples of oils, surfactants, and cosurfactants.

Conflicts of Interest: The authors declare no conflicts of interest.

\section{References}

1. Javed, S.; Kohli, K. Local delivery of minocycline hydrochloride: A therapeutic paradigm in periodontal diseases. Curr. Drug Deliv. 2010, 7, 398-406. [CrossRef] [PubMed]

2. Vyas, S.P.; Sihorkar, V.; Mishra, V. Controlled and targeted drug delivery strategies towards intraperiodontal pocket diseases. J. Clin. Pharm. Ther. 2000, 25, 21-42. [CrossRef] [PubMed]

3. Haffajee, A.D.; Socransky, S.S. Microbial etiological agents of destructive periodontal diseases. Periodontol. 2000 1994, 5, 78-111. [CrossRef] [PubMed]

4. Lamster, I.B.; Novak, M.J. Host mediators in gingival crevicular fluid: Implications for the pathogenesis of periodontal disease. Crit. Rev. Oral Biol. Med. 1992, 3, 31-60. [CrossRef] [PubMed]

5. Löe, H. Periodontal disease. The sixth complication of diabetes mellitus. Diabetes Care 1993, 16, 329-334. [CrossRef]

6. Tonetti, M.S.; Van Dyke, T.E.; Working Group 1 of the Joint EFP/AAP Workshop. Periodontitis and atherosclerotic cardiovascular disease: Consensus report of the Joint EFP/AAPWorkshop on Periodontitis and Systemic Diseases. J. Periodontol. 2013, 84, S24-S29. [CrossRef] [PubMed]

7. De Pablo, P.; Chapple, I.L.C.; Buckley, C.D.; Dietrich, T. Periodontitis in systemic rheumatic diseases. Nat. Rev. Rheumatol. 2009, 5, 218-224. [CrossRef] [PubMed]

8. Devanoorkar, A.; Kathariya, R.; Guttiganur, N.; Gopalakrishnan, D.; Bagchi, P. Resistin: A potential biomarker for periodontitis influenced diabetes mellitus and diabetes induced periodontitis. Dis. Markers 2014, 2014, 1-7. [CrossRef] [PubMed]

9. Tsao, T.-F.; Newman, M.G.; Kwok, Y.-Y.; Horikoshi, A.K. Effect of Chinese and western antimicrobial agents on selected oral bacteria. J. Dent. Res. 1982, 61, 1103-1106. [CrossRef] [PubMed] 
10. Khalessi, A.M.; Pack, A.R.C.; Thomson, W.M.; Tompkins, G.R. An in vivo study of the plaque control efficacy of Persica ${ }^{\mathrm{TM}}$ : A commercially available herbal mouthwash containing extracts of Salvadora persica. Int. Dent. J. 2004, 54, 279-283. [CrossRef] [PubMed]

11. Gulzar Ahmed, M.; Choudhari, R.; Acharya, A. Formulation and evaluation of in situ gel of atorvastatin for the treatment of periodontitis. RGUHS J. Pharm. Sci. 2015, 5, 53-60. [CrossRef]

12. Ranjan, R.; Patil, S.R.; Veena, H.R. Effect of in-situ application of simvastatin gel in surgical management of osseous defects in chronic periodontitis-A randomized clinical trial. J. Oral Biol. Craniofac. Res. 2017, 7, 113-118. [CrossRef] [PubMed]

13. Rawat, S.; Warade, S.; Lahoti, S. In situ gel formulation of ornidazole for the treatment of periodontal disease. Curr. Pharma Res. 2010, 1, 60-69.

14. Sapra, P.; Patel, D.; Soniwala, M.; Chavda, J. Development and optimization of in situ periodontal gel containing Levofloxacin for the treatment of periodontal diseases. J. Sci. Innov. Res. JSIR 2013, 2, 607-626.

15. Aiswarya, G.; Reza, K.; Rajan, R. Development, evaluation, and optimization of flurbiprofen nanoemulsions gel using quality by design concept. Asian J. Pharm. 2015, 9, 35-43. [CrossRef]

16. Geoghegan, F.; Wong, R.W.K.; Rabie, A.B.M. Inhibitory effect of quercetin on periodontal pathogens in vitro. Phyther. Res. 2009, 24, 817-820. [CrossRef]

17. Gómez-Florit, M.; Monjo, M.; Ramis, J.M. Quercitrin for periodontal regeneration: Effects on human gingival fibroblasts and mesenchymal stem cells. Sci. Rep. 2015, 5, 16593. [CrossRef] [PubMed]

18. Napimoga, M.H.; Clemente-Napimoga, J.T.; Macedo, C.G.; Freitas, F.F.; Stipp, R.N.; Pinho-Ribeiro, F.A.; Casagrande, R.; Verri, W.A. Quercetin inhibits inflammatory bone resorption in a mouse periodontitis model. J. Nat. Prod. 2013, 76, 2316-2321. [CrossRef] [PubMed]

19. Cai, X.; Fang, Z.; Dou, J.; Yu, A.; Zhai, G. Bioavailability of quercetin: Problems and promises. Curr. Med. Chem. 2013, 20, 2572-2582. [CrossRef] [PubMed]

20. Tran, T.H.; Guo, Y.; Song, D.; Bruno, R.S.; Lu, X. Quercetin-containing self-nanoemulsifying drug delivery system for improving oral bioavailability. J. Pharm. Sci. 2014, 103, 840-852. [CrossRef] [PubMed]

21. Chabane, M.N.; Ahmad, A.A.; Peluso, J.; Muller, C.D.; Ubeaud, G. Quercetin and naringenin transport across human intestinal Caco-2 cells. J. Pharm. Pharmacol. 2009, 61, 1473-1483. [CrossRef]

22. Gao, L.; Liu, G.; Wang, X.; Liu, F.; Xu, Y.; Ma, J. Preparation of a chemically stable quercetin formulation using nanosuspension technology. Int. J. Pharm. 2011, 404, 231-237. [CrossRef] [PubMed]

23. Gao, Y.; Wang, Y.; Ma, Y.; Yu, A.; Cai, F.; Shao, W.; Zhai, G. Formulation optimization and in situ absorption in rat intestinal tract of quercetin-loaded microemulsion. Colloids Surf. B Biointerfaces 2009, 71, 306-314. [CrossRef] [PubMed]

24. Li, H.; Zhao, X.; Ma, Y.; Zhai, G.; Li, L.; Lou, H. Enhancement of gastrointestinal absorption of quercetin by solid lipid nanoparticles. J. Control. Release 2009, 133, 238-244. [CrossRef] [PubMed]

25. Park, K.H.; Choi, J.M.; Cho, E.; Jeong, D.; Shinde, V.V.; Kim, H.; Choi, Y.; Jung, S. Enhancement of solubility and bioavailability of quercetin by inclusion complexation with the cavity of mono-6-deoxy-6-aminoethylamino- $\beta$-cyclodextrin. Bull. Korean Chem. Soc. 2017, 38, 880-889. [CrossRef]

26. Azuma, K.; Ippoushi, K.; Ito, H.; Higashio, H.; Terao, J. Combination of lipids and emulsifiers enhances the absorption of orally administered quercetin in rats. J. Agric. Food Chem. 2002, 50, 1706-1712. [CrossRef] [PubMed]

27. Patel, R.P.; Joshi, J.R. An overview on nanoemulsion: A novel approach. Int. J. Pharm. Sci. Res. 2012, 3, 4640-4650.

28. Sherje, A.P.; Kulkarni, V.; Murahari, M.; Nayak, U.Y.; Bhat, P.; Suvarna, V.; Dravyakar, B. Inclusion complexation of etodolac with hydroxypropyl-beta-cyclodextrin and auxiliary agents: Formulation characterization and molecular modeling studies. Mol. Pharm. 2017, 14, 1231-1242. [CrossRef] [PubMed]

29. Suvarna, V.; Thorat, S.; Nayak, U.; Sherje, A.; Murahari, M. Host-guest interaction study of Efavirenz with hydroxypropyl- $\beta$-cyclodextrin and l-arginine by computational simulation studies: Preparation and characterization of supramolecular complexes. J. Mol. Liquids 2018, 259, 55-64. [CrossRef]

30. Ali, H.H.; Hussein, A.A. Oral nanoemulsions of candesartan cilexetil: Formulation, characterization and in vitro drug release studies. AAPS Open 2017, 3, 4. [CrossRef]

31. Chopra, M.; Nayak, U.Y.; Kumar Gurram, A.; Sreenivasa Reddy, M.; Koteshwara, K.B. Formulation, characterization and in vivo evaluation of self-nanoemulsifying drug delivery system for oral delivery of valsartan. Curr. Nanosci. 2014, 10, 263-270. [CrossRef] 
32. Ahmad, J.; Mir, S.R.; Kohli, K.; Chuttani, K.; Mishra, A.K.; Panda, A.K.; Amin, S. Solid-nanoemulsion preconcentrate for oral delivery of paclitaxel: formulation design, biodistribution, and $\gamma$ scintigraphy imaging. Biomed. Res. Int. 2014, 2014, 1-12. [CrossRef] [PubMed]

33. Srivastava, M.; Kohli, K.; Ali, M. Formulation development of novel in situ nanoemulgel (NEG) of ketoprofen for the treatment of periodontitis. Drug Deliv. 2016, 23, 154-166. [CrossRef] [PubMed]

34. Srivastava, M.; Neupane, Y.R.; Kumar, P.; Kohli, K. Nanoemulgel (NEG) of Ketoprofen with eugenol as oil phase for the treatment of ligature-induced experimental periodontitis in Wistar rats. Drug Deliv. 2016, 23, 2228-2234. [CrossRef] [PubMed]

35. Garala, K.; Joshi, P.; Patel, J.; Ramkishan, A.; Shah, M. Formulation and evaluation of periodontal in situ gel. Int. J. Pharm. Investig. 2013, 3, 29-41. [CrossRef] [PubMed]

36. Holz, M.; Heil, S.R.; Sacco, A. Temperature-dependent self-diffusion coefficients of water and six selected molecular liquids for calibration in accurate 1 H NMR PFG measurements. Phys. Chem. Chem. Phys. 2000, 2, 4740-4742. [CrossRef]

37. Sharma, N.; Mishra, S.; Sharma, S.; Deshpande, R.D.; Sharma, R.K. Preparation and optimization of nanoemulsions for targeting drug delivery. Int. J. Drug Dev. Res. 2013, 5, 37-48.

38. Patil, A.; Mahale, S.; Joshi, C.; Karde, P.; Vaidya, P. Honey as a Potential Antimicrobial Agent against P. gingivalis. Int. J. Contemp. Med. Res. 2016, 3, 2697-2700.

39. Nayak, U.Y.; Gopal, S.; Mutalik, S.; Ranjith, A.K.; Reddy, M.S.; Gupta, P.; Udupa, N. Glutaraldehyde cross-linked chitosan microspheres for controlled delivery of Zidovudine. J. Microencapsul. 2009, 26, $214-222$. [CrossRef] [PubMed]

Sample Availability: Not available.

(C) 2018 by the authors. Licensee MDPI, Basel, Switzerland. This article is an open access article distributed under the terms and conditions of the Creative Commons Attribution (CC BY) license (http://creativecommons.org/licenses/by/4.0/). 